\title{
Hamartoma of the Head and Neck
}

\author{
R. K. Jain, Reader, Department of E.N.T., Institute of Medical Sciences, \\ Banaras Hindu University, Varanasi-221 005, India.
}

\begin{abstract}
Hamartoma is a relatively uncommon lesion in head and neck region. Although hamartoma is not a true neoplasm, but it behaves in tumour like manner in many ways. In this paper five cases of hamartoma of head and neck region, one case each from soft tissue cheek, soft tissue neck, maxilla, gum margin and tongue are reported and pertinent literature is reviewed.
\end{abstract}

\section{Key Words}

Hamartoma, Teratoma; Dermoid; Teratoids; Charistoma.

\section{INTRODUCTION}

The term hamartoma (hamartia, error (Gr.) was introduced by Albrecht (1904) to designate tumour like, but non-neoplastic malformations or inborn errors in the development of one of the three germinal layers. Mamartomas are characterised by abnormal mixture of tissue, indigenous to the part from which it arise. Such malformations produce an excessive number of cells which reach the maturity and them cease to reproduce, so the growth is selflimiting. The term hamartoma should be used only when there is definite evidence of a developmental anomaly. These malformations includes not only errors of development since birth but also the inborn tissue anomaly which manifests itself by excessive growth untill the age of puberty (Willis, 1953).

Hamartomas frequently arise from skin or subcutaneous tissue, kidney, lung, liver, spleen and gastro-intestinal tract. These tumours however are rarely encountered in otolaryngological practice where they mostly occur as hairy polyps in nasopharynx (Branderburg et al., 1977; Ladapo, 1988). Here five cases of hamartoma arising from various sites of the head and neck, which treated at our centre, are being reported.

\section{Case 1}

J.S. 18 Yrs. $M$ attended E.N.T. outdoor with the complaint of gradually increasing swelling over the right cheek since birth. The swelling was stationary for the last 2-3 years. On examination a swelling of $8 \times 8 \mathrm{cms}$. in size, extending from lips to angle of manible was seen (Fig. 1). It was non tender and well defined. In the central region skin was adherant to the tumour mass. From the buccal side firm nodules could be palpated in the swelling. Patient was admitted and investigated. Routine investigations were within normal limit. Patient was operated under C.A. and wide excision of growth along with reconstruction of cheek was done. Histopathological examination confirmed the diagnosis of meurofibromatous hamartoma.

\section{Case 2}

S.L. 15 Yrs. $M$ was referred to us from Dental Services. Patient had a pain less progressive swelling over the left upper jaw for the last 10 years. The swelling was hard. The gingive labial sulcus was completely obliterated. The teeth from left central incissor to second molar were displaced. The swelling had also in- 


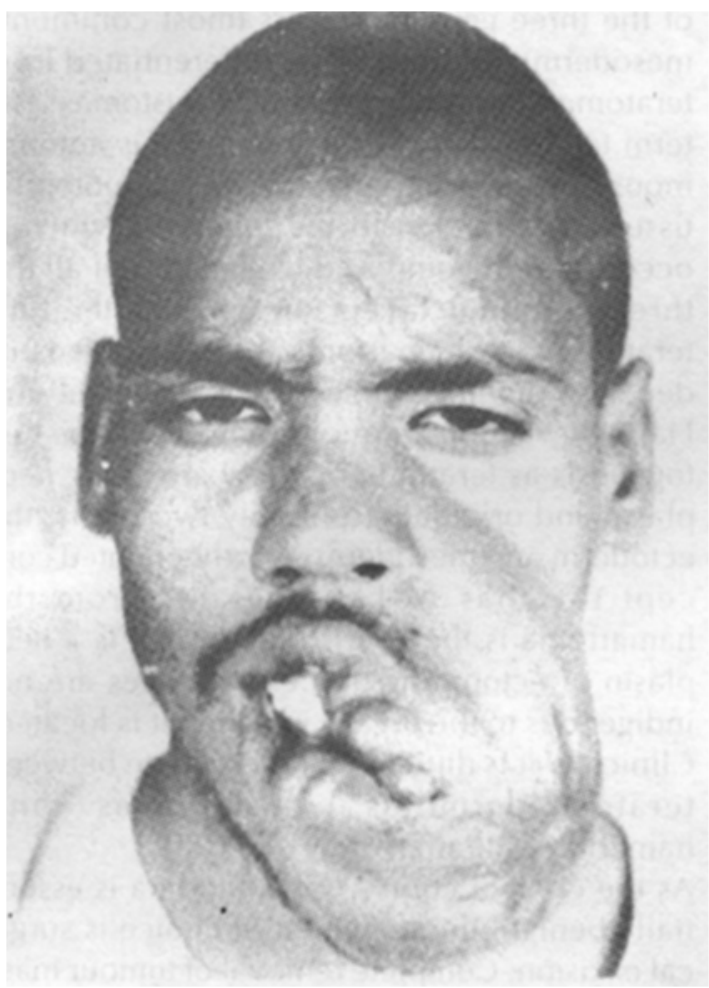

Fig. 1. Clinical photograph of the Case 1

volved left side of palate. Patient was admitted and investigated. Skiagrams of Para Nasal Sinuses revealed opacified left maxillary antrum. There was no bony erosion or destruction. Patient was operated and left sided partial maxillectomy was done. Histopathological examination established the diagnosis of sclerosing angiomatous hamartoma of maxilla.

\section{Case 3}

M.A. 14 Yrs. M presented with irregular pedunculated swelling over left upper gum margin in the region of first molar. The swelling was present since last seven years. It was non tender and firm in consistancy. Its surface was irregular. There was history of recurrent mild bleeding from swelling. Patient was provisionally diagnosed as a case of epulis and wide excision of tumour was done. Histopathological examination revealed it as a vascular hamartoma.

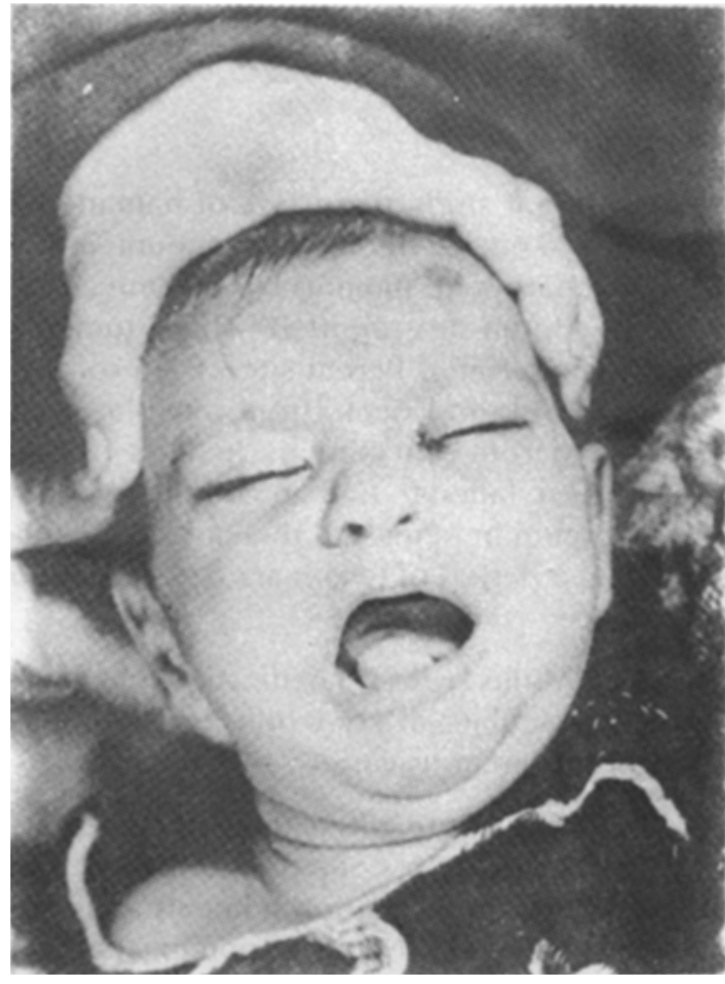

Fig. 2. Clinical photograph of Case 5.

\section{Case 4}

A.A. 15 Yrs. $M$ attended E.N.T. outdoor with painless progressive swelling in right supra clavicular fossa since last eight years. Size of swelling was $6 \times 6 \mathrm{cms}$. Its margins were ill defined and merged imperceptably with the surrounding structures. The tumour was superfecial to sternomastoid muscle. The tumour mass was excised. Misto-pathological examination established the diagnosis of vascular hamartoma.

\section{Case 5}

Y.K. 3 Yrs. F was braught to E.N.T. outdoor for swelling over the ventral surface of tongue (Fig. 3 ). The swelling was present since birth and gradually increasing in size. It was non tender. It's margins were well defined and surface was smooth. Its consistency was firm. The wide excision of tumour was done. The histopatho- 
logical examination confirmed the diagnosis of vascular hamartoma.

\section{Discussion}

In the present study five cases of hamartoma of head and neck, which were encountered in E.N.T. Department, Banaras Hindu University, Varanasi, India are reported. These tumours were arising from different sites, from soft tissues of cheek and neck, from maxilla, from tongue and from gum margins. In the reviewed literature we failed to find any other case arising from gum margins. All the cases were followed up a period of two years. These was no recurrance.

As per the Willis (1968) classification four cases were of vascular variety while first case was of neurofibromatous variety.

A hamartoma more often than not presents many clinical features of a tumour though basically it is a malformation. Hamartomas are composed exclusively of components derived from local tissues (Willis, 1969). They grow concurrently with the host forming a mass of recongnizable but unorgarised tissues which contains examples of structure derived from any of the three germinal layers (most commonly mesoderm). These must be differentiated from teratomas, dermoid cysts and choristomas. The term teratoma implies a spontaneous autonomous new growth derived from pluripotential tissue. It is foreign to the region in which it occurs and in composed of elements of all the three germinal layers. In earlier literature teratomas and hamartomas were included under the common name teratoids (Eichel and Hallberg, 1966). Dermoids have the same histogenesis as teratoma but they are cystic neoplasm and originate from only two layers, the ectoderm and mesoderm. Another related concept that has to be seperated from the hamartoma is the charistoma which is a neoplasm of ectopic tissue i.e. its tissues are not indigenous to the organs in which it is located. Clinically it is difficult to differentiate between teratoma,dermoids, charistomas and hamartomas (Patterson et al., 1981).

As the clinical course of hamartoma is essentially benign, the treatment of choice is surgical excision. Complete removal of tumour mass by wide surgical excision seems ideal to deal such conditions. Once tumour mass completely removed there are no chances of recurrence.

\section{References}

1. Albrecht, E. (1904). Verhandlungen der Deutschen pathologischen Gesellschaft, 7, 153-157. Pathology of Tumours. Cited by Willis, RA (1958). 3rd ed. Butterworths, London, pp 7.

2. Branderburg, JH; Finch, WW and Lloyd, R. (1977). Cystic hamartoma of nasopharynx. Am. Acad. Ophthalmol. Otolaryngol., 82, 152 - 153.

3. Eichel, BS and Hallberg, OE. (1966). Hamartoma of the middle ear, and eustachian tube. Laryngoscope, 76, 1810-1815.

4. Ladapo, AA. (1988). A case of benign hamartoma of nasopharynx. J. Laryngology \& Otology, 92, $1141-1145$.

5. Patterson, HC; Dickerson, GR; Pilch, BZ and Benthover, SH. (1981). Hamartoma of the nasopharynx. Archives of Otolaryngology, 107, $767-772$.

6. Willis, RA (1953). Pathology of tumours. 2nd ed, Butterworth, London, pp 662.

7. Willis, RA. (1967). Pathology of tumours. 4th ed, Butterworth, London, pp 959.

8. Willis RA (1968). Some unusual developmental neteropias. Brit. Med. J., 3, 267 - 272. 